\title{
Diagnosis of Premature Senescence of Cotton Using SPAD Value
}

\author{
Pengcheng Li, Helin Dong*, Aizhong Liu, Jingran Liu, Miao Sun, Guoping Wang, \\ Siping Zhang, Yabing Li, Shuchun Mao \\ Institute of Cotton Research of Chinese Academy of Agricultural Sciences, \\ State Key Laboratory of Cotton Biology, Anyang, China \\ Email: donghl@cricaas.com.cn
}

Received 26 July 2014; revised 28 August 2014; accepted 18 September 2014

Copyright (C) 2014 by authors and Scientific Research Publishing Inc.

This work is licensed under the Creative Commons Attribution International License (CC BY).

http://creativecommons.org/licenses/by/4.0/

(c) (i) Open Access

\section{Abstract}

Field experiments were conducted in 2011 on an experimental farm at the Cotton Research Institute, Chinese Academy of Agricultural Sciences, Anyang, China. We conducted experiments with a "SPAD-502" meter to quickly measure the relative value of chlorophyll content in the leaf blades of field cotton. Our goal was to seek a suitable leaf on a cotton plant to diagnose senescence status of crop plants at later stages of growth. We began by studying the dynamic change rule of the distal-most four leaves of the cotton plant during the entire growth period with two early-maturing cultivars (CCRI 36, CCRI 50) and two mid-maturing cultivars (CCRI 41, SCRC 28). We also examined the effect of different nitrogen and potassium fertilizer rates on SPAD values of the leaves of SCRC 28. Our results suggest that SPAD values of the 1st distal stem leaves from two early cultivars can act as good indicators of senescence status in the plants, if they are measured between $10 \mathrm{~d}$ before the boll-opening stage and $10 \mathrm{~d}$ after boll opening stage. Differences of SPAD values of the 3rd distal stem leaves of two mid-maturing cultivars measured between about $15 \mathrm{~d}$ before the boll opening stage and $15 \mathrm{~d}$ after the boll opening stage can also be used to measure senescence status in these cotton cultivars. The conclusion can be used for cotton producer to manage $\mathbf{N}$ fertilizer better at later growth stage.

\section{Keywords}

Diagnosis, Premature Senescence, Cotton (Gossypium hirsutum L.), SPAD Values

\section{Introduction}

Nitrogen $(\mathrm{N})$ is the nutrient that most often limits crop production and the nutrient that requires the most ex-

\footnotetext{
${ }^{*}$ Corresponding author.
}

How to cite this paper: Li, P.C., Dong, H.L., Liu, A.Z., Liu, J.R., Sun, M., Wang, G.P., Zhang, S.P., Li, Y.B. and Mao, S.C. (2014) Diagnosis of Premature Senescence of Cotton Using SPAD Value. Agricultural Sciences, 5, 992-999. 
pense and effort to add to the soil to meet crop requirements. Due to the detrimental effects of limited or excess $\mathrm{N}$ on cotton (Gossypium hirsutum L.), it is desirable to monitor crop $\mathrm{N}$ status so that management changes can be made in order to optimize yield and quality [1].

The leaves of cotton are the main organs for photosynthesis and chlorophyll is an important pigment by which chemical energy can be transformed to light energy [2]. There is a direct relationship between the chlorophyll content in leaves and the amount of photosynthesis occurring there. The solar radiation absorbed by a leaf blade is dependent on its chlorophyll content and so chlorophyll contents may be used as a gauge of the nutritional status and age of crop plants.

The traditional determination method of leaf chlorophyll content is labor intensive. Chlorophyll must be extracted from leaf samples, destroying the leaves in the process. However a "SPAD-502" meter (made in Japan) can quickly measure the relative value of chlorophyll content in leaf blades and this information can be used to diagnose the nutrition status of crop plants. In recent years, the chlorophyll meter has been widely used in rapidly and indirectly measuring the nutrients of leaves in rice [3], wheat [4] [5], corn [6], rape [7], potato [8], watermelon [9], cucumber [10] and other crops. SPAD values of leaves have also been used in the remote sensing of cotton [11].

Research on several different crop species has focused on determing the relationship between leaf SPAD values and plant $\mathrm{N}$ content at different growth stages. This information can be used to quickly and accurately diagnose the $\mathrm{N}$ requirements of a crop and allow for the appropriate levels of $\mathrm{N}$ fertilizer application. Wang et al. [3] reported that in rice the health of the fourth leaf is a good indication of the plant's nutrition status. They found that color differences between the third and fourth leaves were highly correlated to the plant's $\mathrm{N}$ content, regardless of variety and development stage.

SPAD values can also be used to estimate $\mathrm{N}$ status in wheat plants [12], although SPAD values of different leaves of the same cultivar may have no obvious relationship with the total plant $\mathrm{N}$ content. SPAD data should be collected from different parts of the wheat leaf to carefully diagnose $\mathrm{N}$ content in the individual plant.

Jiang et al. [6] found that the best time to fertilize corn was at the 10-leaf stage when the SPAD value of the ear leaf had slightly decreased, but the SPAD value of the distal leaf had reached its maximum at heading stage, and then decreased. Qiu et al. [13] analyzed the SPAD values in fully-expanded leaves in the third branch and their results suggested that the time between bud and anthesis was the best period for $\mathrm{N}$ fertilizer application.

Nie et al. [8] obtained SPAD values throughout the growth stages of potato plants and found that they closely tracked $\mathrm{N}$ status. The authors concluded that SPAD values can be used to accurately determine the appropriate times to apply $\mathrm{N}$ to potato crops.

Hong et al. [9] studied watermelons and found that there is a significant correlation between SPAD values and $\mathrm{N}$ content of the leaves in the upper leaf of the seedling stage and the lower leaf of the vineing stage. SPAD values measured from these fragile leaves can be used to diagnose $\mathrm{N}$ nutrient requirements during sensitive growth periods.

Wu et al. [10] found that there was a good correlation between the content of nitrate and the SPAD values of leaves during flowering and fruiting in cucumbers.

There have been many studies on the chlorophyll content of cotton leaves assessed with chlorophyll meters [14] [15]. Chlorophyll content increased in cotton leaves when plants were subjected to drip irrigation below the film [16]. These studies drew inconsistent conclusions about the sensitivity of cotton leaves to $\mathrm{N}$ application. Some investigations indicated that the fourth leaf was extremely sensitive to $\mathrm{N}$, while the second leaf was relatively insensitive to $\mathrm{N}$, and the first and third leaves varied between the cotton varieties [17]. Qu et al. [18] found that cauline leaf SPAD values at different positions on two cultivars responded differently to increasing $\mathrm{N}$ rate. The first fully-expanded cauline leaf (SL1) was most sensitive, while the fourth fully-expanded leaf (SL4) responded the least. As the N application rate increased, the SL4 and SL1 in the two cultivars converged on a similar SPAD value. The leaves could be well-characterized by the relative positional difference index (PDI), reflecting the greenness difference between SL1 and SL4. PDI can be an ideal indicator of cotton N status. Another study found that leaf SPAD values can also be used to estimate the degree of senescence in cotton leaves [19]. In the study they compared SPAD values on the day of flowering and $35 \mathrm{~d}$ after flowering as an indicator of chlorophyll content reduction, to measure the rate of reduction, and to track senescence [19]. Wu et al. [20] obtained the optimum SPAD values at different crop development stages when $\mathrm{N}$ was applied in appropriate topdressing amount.

Wood et al. [21] indicated that hand-held chlorophyll meters would be as reliable as destructive sampling of 
leaf-blade $\mathrm{N}$ and petiole $\mathrm{NO}_{3}-\mathrm{N}$ for predicting supplemental $\mathrm{N}$ fertilization requirements in cotton. They found that more research was necessary before chlorophyll meter readings could be routinely used to predict cotton $\mathrm{N}$ requirements.

Johnson et al. [22] indicated that the Minolta SPAD 502 Chlorophyll Fluorescence Meter has proven to be the most reliable hand held meters for infield readouts when monitoring $\mathrm{N}$ in cotton. Yet, this meter has its limitations when it comes to distinguishing between levels of N. The SPAD meter was able to detect between plots with no additional $\mathrm{N}$ application and plots with $\mathrm{N}$ applied during the first week of bloom. However, the SPAD meter was unable to distinguish between levels of $\mathrm{N}$ application during the first week of bloom. Bob et al. [1] reported that a chlorophyll meter was able to track the relationship between $\mathrm{N}$ fertilizer application and chlorophyll content within a limited period of time, but readings exhibited a large amount of variability between dates, suggesting a lack of precision in the measurements.

A correlation analysis and partitioning through a path coefficient analysis revealed that leaf chlorophyll content may be one of the major factors influencing seed cotton yield under drought stress [23].

A promising approach to measuring the $\mathrm{N}$ status in cotton was suggested by El-Shikha et al. [6]. Their approach involves predicting $\mathrm{N}$-sufficient and $\mathrm{N}$-stressed limits as a function of crop cover and then calculating a normalized index between these limits to form what is referred to as the Canopy Chlorophyll Concentration Index (CCCI). Ciro and Vanessa [24] reported that chlorophyll meters can also be used to estimate the nutritional status of cotton from the 3rd week of flowering and that the optimal reading is above 48 in well-nourished cotton plants. Raper et al. [25] indicated that digital image analysis (a dark green color index) was a practical and inexpensive method sensitive to cotton $\mathrm{N}$ status that could potentially replace chlorophyll meters.

Most research on cotton has focused on sampling the fourth cauline leaf, but even though studies have sampled the same structure on the plant there have been some limitations when comparing SPAD values across various cotton genotypes. The difference in SPAD values among the upper four cauline leaves of several cotton varieties has not been previously studied, although this information is necessary to properly assess previous reports. We chose two early-maturing cultivars and two mid-maturing cotton cultivars and studied the change in SPAD values among the upper four cauline leaves across the plant's developmental stages. Additionally, we assessed the effects of different $\mathrm{N}$ and $\mathrm{P}$ fertilizer regimens on SPAD values, with the goal of determining the best leaf on the plant for senescence diagnosis of plant at late growth stages of cotton.

\section{Materials \& Methods}

\subsection{Study Site}

Field experiments were conducted at an experimental farm at the Institute of Cotton Research, Chinese Academy of Agricultural Sciences, Anyang, China $\left(36^{\circ} 07^{\prime} \mathrm{N}, 116^{\circ} 22^{\prime} \mathrm{E}, 76 \mathrm{~m}\right.$ above sea level) in 2011. The soil at the farm is a moist loam soil containing $1.51 \%$ organic matter, $0.083 \%$ total $\mathrm{N}, 30 \mathrm{mg} \cdot \mathrm{kg}^{-1} \mathrm{P}_{2} \mathrm{O}_{5}$, and $30 \mathrm{mg} \cdot \mathrm{kg}^{-1}$ $\mathrm{K}_{2} \mathrm{O}$ within a depth of $0-20 \mathrm{~cm}$. Cotton was planted with a plastic film mulch.

\subsection{Experimental Design and Crop Cultivation}

Two early-maturing cultivars of cotton (Gossypium hirsutum L.) CCRI 36 and CCRI 50 and two mid-maturing cultivars of cotton CCRI 41 were provided by the Institute of Cotton Research, Chinese Academy of Agricultural Sciences. SCRC 28 was provided by the Cotton Research Center, Shandong Academy of Agricultural Sciences. These five varieties were planted in field trials in which $\mathrm{N}$ was applied at a rate of $180 \mathrm{~kg} \cdot \mathrm{ha}^{-1}$ and $\mathrm{P}_{2} \mathrm{O}_{5}$ and $\mathrm{K}_{2} \mathrm{O}$ were applied at a rate of $120 \mathrm{~kg} \cdot \mathrm{ha}^{-1}$.

CCRI 36 and SCRC 28 were planted in the second trial that varied the application rate of $\mathrm{N}$ and $\mathrm{K}$. In the $\mathrm{N}$ treatments $\mathrm{P}_{2} \mathrm{O}_{5}$ and $\mathrm{K}_{2} \mathrm{O}$ were applied at $120 \mathrm{~kg} \cdot \mathrm{ha}^{-1}$, while the amount of $\mathrm{N}$ was either $0 \mathrm{~kg} \cdot \mathrm{ha}^{-1}(\mathrm{~N} 1)$ or 360 $\mathrm{kg} \cdot \mathrm{ha}^{-1}\left(\mathrm{~N}_{2}\right)$. In the K treatments $\mathrm{N}$ and $\mathrm{P}_{2} \mathrm{O}_{5}$ were applied at $180 \mathrm{~kg} \cdot \mathrm{ha}^{-1}$ and $120 \mathrm{~kg} \cdot \mathrm{ha}^{-1}$, while the amount of $\mathrm{K}_{2} \mathrm{O}$ was either $0 \mathrm{~kg} \cdot \mathrm{ha}^{-1}(\mathrm{~K} 1)$ or $240 \mathrm{~kg} \cdot \mathrm{ha}^{-1}(\mathrm{~K} 2)$. In the experiments above, half of the $\mathrm{N}$ fertilizer was applied before planting and half was applied at the first bloom stage. The full amount of $\mathrm{P}$ and $\mathrm{K}$ fertilizer was applied before planting. Four replicates of each treatment were planted in randomly arranged plots $56 \mathrm{~m}^{2}(10 \mathrm{~m} \times 5.6 \mathrm{~m})$ with a row space of $80 \mathrm{~cm}$. The two early cultivars were sown on May 20 at a density of 52,500 and the two mid-maturing cultivars were sown on April 26 at a density of 75,000. Seedlings were thinned to the planned density at the first-leaf and third-leaf stage. Field management was conducted according to local practice. 


\subsection{Sampling and Measurements}

During the field trials, date of cotton seedling emergence, squaring, flowering, and boll-opening were recorded from 15 successive plants. SPAD values were measured for the upper four, fully-expanded leaves with a "SPAD-502" meter during sunny days between 0900 and 1100. During the measurement a normal leaf was cleaned and divided into four sections in which SPAD values were tested three times. The average SPAD value of the four leaf sections was used to approximate the SPAD value for the whole leaf. Twenty plants within each plot were randomly selected for measurement. Leaves of the two early-maturing cultivars were measured at $10 \mathrm{~d}$ intervals from June 11 until September 2, while leaves of the two medium-maturing cultivars were measured at 15 d intervals from June 7 until September 5.

\subsection{Calculation and Statistical Analysis}

Microsoft Excel 2010 was used to record the data and produce graphs. SAS 9.1 was used for the ANOVA analysis.

\section{Results and Discussion}

\subsection{SPAD Values of Cotton Leaves at Different Life Stages}

In the two trials, the emergence stage of CCRI 36 (Gossypium hirsutum L.) and CCRI 50 began on May 27, the flowering stage began on July 12, and the boll-opening stage began on August 23. In the first trial the SPAD values of the upper four leaves of the two early-maturing cultivars decreased from June 11 to July 12 and then rose to the maximum on August 13, declining again on September 2. During the entire growth period, the SPAD values of the first leaves were lower than the SPAD values of the second leaves, and so on until the maximum SPAD values were measured in the fourth leaves (Figure 1).

SPAD values were measured for four different leaves between August 13 and September 2 in two early-maturing cotton cultivars. The first leaf had a much higher value than the three lower leaves (Table 1 ) and this difference can be used as a reference for senescence diagnosis of cotton plants.

In two trials the emergence stage of SCRC 28 and CRI 41 began on May 3, the flowering stage began on July 6, and the boll-opening stage began on August 21. In the first trial the SPAD values of the four upper leaves of SCRC 28 and CRI 41 first declined, but then the values for SCRC 28 rose on June 28 and the values for CRI 41 rose on July 8. The maximum SPAD values of SCRC 28 and CRI 41 occurred on August 6 and then began declining on September 5. Between August 6 and September 5 (during the full boll period), SPAD values of the first leaves were less than those of the second leaves and the second leaves were less than the third, and so on, with the fourth leaves having the highest SPAD values (Figure 1).

SPAD values were measured for several leaves in two medium-maturing cotton cultivars between August 6 and September 5 and the values were much higher in the third leaf than the values in the other three leaves (Table 2). This difference could serve as a reference for senescence diagnosis of cotton plants.

\subsection{The Effect of $\mathbf{N}$ and $\mathrm{K}$ Fertilizer Rates on SPAD Values of Cotton Cultivar CRI 36}

In the fertilizer experiment SPAD values were measured in the upper leaves of CRI 36. Values were higher on August 13 than on September 2. In the N1 and K1 plants the SPAD values of upper leaves were lower than val-

Table 1. The SPAD values of upper leaves of 2 early-maturing cotton cultivars at later growth periods.

\begin{tabular}{|c|c|c|c|c|c|c|}
\hline \multirow{2}{*}{ Leaf site } & \multicolumn{3}{|c|}{ CRI 50} & \multicolumn{3}{|c|}{ CRI 36} \\
\hline & Aug. 13 & Sep. 02 & Difference & Aug. 13 & Sep. 02 & Difference \\
\hline The $1^{\text {st }}$ leaf from the top & $51.6 \pm 6.2^{b}$ & $39.5 \pm 5.4^{\mathrm{b}}$ & $12.1 \pm 0.38^{\mathrm{a}}$ & $51.6 \pm 4.7^{b}$ & $41.3 \pm 1.8^{\mathrm{b}}$ & $10.3 \pm 0.11^{\circ}$ \\
\hline The $2^{\text {nd }}$ leaf from the top & $56.8 \pm 3.7^{b}$ & $46.7 \pm 4.1^{\mathrm{b}}$ & $10.1 \pm 0.50^{\mathrm{b}}$ & $53.6 \pm 1.6^{\mathrm{b}}$ & $44.9 \pm 3.2^{\mathrm{b}}$ & $8.7 \pm 0.19^{b}$ \\
\hline The $3^{\text {rd }}$ leaf from the top & $59.1 \pm 2.1^{\mathrm{a}}$ & $48.3 \pm 1.3^{\mathrm{a}}$ & $10.8 \pm 0.10^{\mathrm{b}}$ & $55.9 \pm 1.8^{\mathrm{a}}$ & $48.4 \pm 3.2^{\mathrm{a}}$ & $7.5 \pm 0.28^{\mathrm{b}}$ \\
\hline The $4^{\text {th }}$ leaf from the top & $59.0 \pm 2.4^{\mathrm{a}}$ & $48.1 \pm 2.2^{\mathrm{a}}$ & $10.9 \pm 0.15^{\mathrm{b}}$ & $57.9 \pm 5.7^{\mathrm{a}}$ & $52.1 \pm 2.4^{\mathrm{a}}$ & $5.8 \pm 0.62^{c}$ \\
\hline
\end{tabular}

Note: "Difference" means the SPAD values on Aug. 13 minus the SPAD values on Sep. 02. Values in the same column followed by different letters indicate significant differences (Duncan $\mathrm{P}<0.05$ ). 

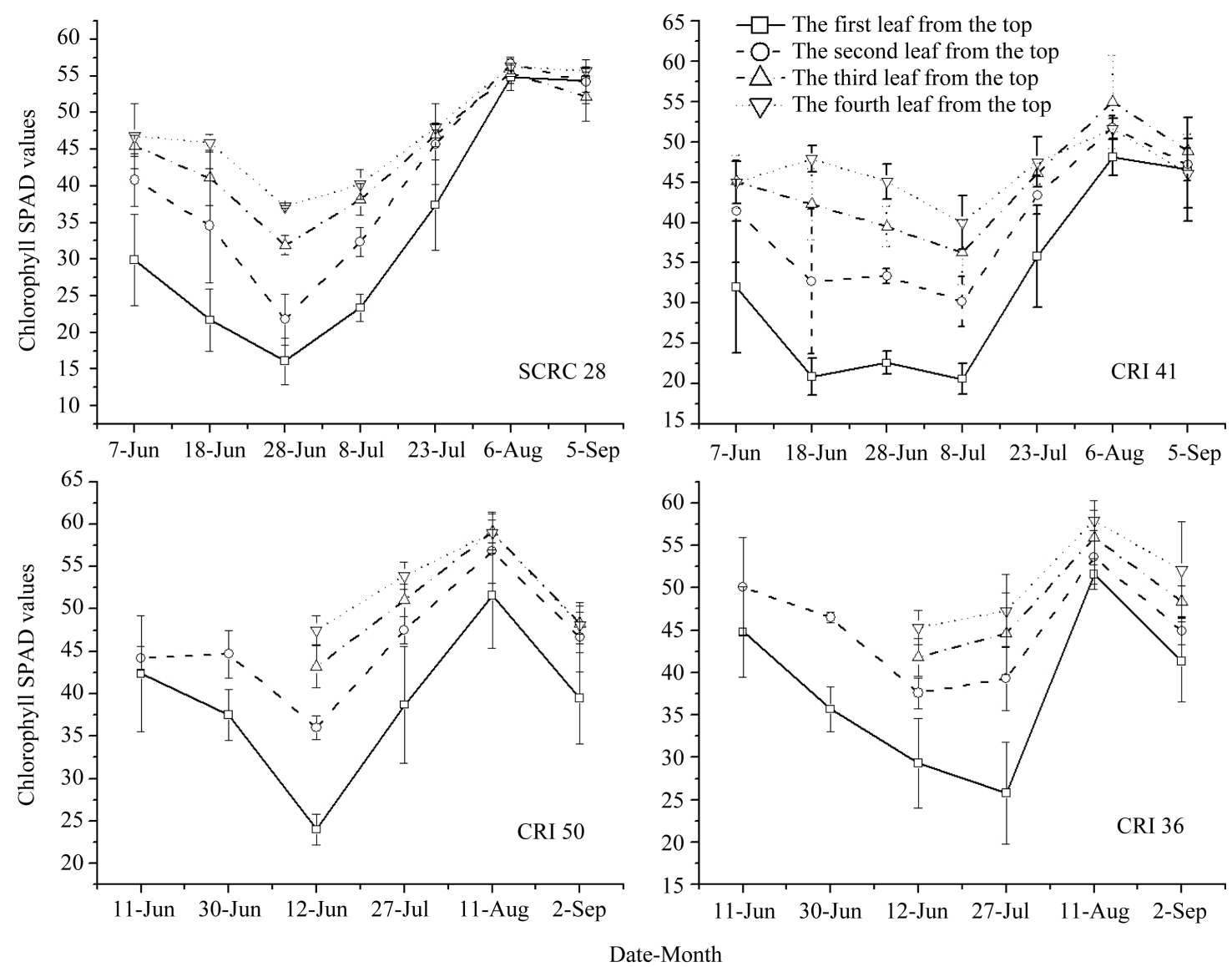

Figure 1. Dynamic changes of SPAD values of upper leaves of cotton plants of different cultivars.

Table 2. The SPAD values of main stem leaves of 2 mid-maturing cultivars at later growth periods.

\begin{tabular}{ccccccc}
\hline \multirow{2}{*}{ Leaf site } & \multicolumn{3}{c}{ SCRC 28} & & CRI 41 \\
\cline { 2 - 6 } & Aug. 06 & Sep. 05 & Difference & Aug. 06 & Sep. 05 & Difference \\
\hline The $1^{\text {st }}$ leaf from the top & $54.8 \pm 1.7^{\mathrm{a}}$ & $54.4 \pm 1.6^{\mathrm{a}}$ & $0.4 \pm 0.13^{\mathrm{c}}$ & $48.1 \pm 2.3^{\mathrm{a}}$ & $46.6 \pm 6.4^{\mathrm{a}}$ & $1.5 \pm 0.37^{\mathrm{c}}$ \\
The $2^{\text {nd }}$ leaf from the top & $56.7 \pm 0.9^{\mathrm{a}}$ & $54.2 \pm 3.0^{\mathrm{a}}$ & $2.5 \pm 0.21^{\mathrm{b}}$ & $51.8 \pm 1.4^{\mathrm{a}}$ & $47.2 \pm 2.0^{\mathrm{a}}$ & $4.6 \pm 0.20^{\mathrm{b}}$ \\
The $3^{\text {rd }}$ leaf from the top & $55.4 \pm 1.4^{\mathrm{a}}$ & $52.2 \pm 3.3^{\mathrm{a}}$ & $3.3 \pm 0.29^{\mathrm{a}}$ & $55.0 \pm 5.8^{\mathrm{a}}$ & $48.9 \pm 2.1^{\mathrm{a}}$ & $6.1 \pm 0.49^{\mathrm{a}}$ \\
The $4^{\text {th }}$ leaf from the top & $56.3 \pm 1.0^{\mathrm{a}}$ & $55.7 \pm 0.6^{\mathrm{a}}$ & $0.6 \pm 0.10^{\mathrm{c}}$ & $51.6 \pm 1.3^{\mathrm{a}}$ & $46.1 \pm 4.3^{\mathrm{a}}$ & $5.5 \pm 0.36^{\mathrm{b}}$ \\
\hline
\end{tabular}

Note: "Difference" means the SPAD values on Aug. 06 minus the SPAD values on Sep. 05. Values in the same column followed by different letters indicate significant differences (Duncan $\mathrm{P}<0.05$ ).

ues measured in the upper leaves of N2 and K2 plants. Between August 13 and September 2 SPAD values of the first leaf of two medium-maturing cotton cultivars were significantly higher than values of the other three leaves. These results are consistent with the results from the first trial (Table 3).

\subsection{The Effect of $\mathbf{N}$ and K Fertilizer Rates on SPAD Values of Cotton Cultivar SCRC 28}

In the fertilizer experiment SPAD values measured in the upper leaves of SCRC 28 on August 6 were higher than SPAD values measured on September 5. SPAD values of upper leaves with the N1 and K1 treatments were lower than those of the N2 and K2 treatments. SPAD values of leaves measured between August 6 and September 5 found that the third leaf was significantly higher than values in the other three leaves. These results were consistent with the first trial (Table 4).

There is a high correlation between the concentration of the photosynthetic pigments chlorophyll a and chlo- 
Table 3. The effect of $\mathrm{N}$ and $\mathrm{K}$ fertilizer on SPAD values of upper leaves from top of CRI 36.

\begin{tabular}{|c|c|c|c|c|}
\hline Treatments & Leaf site & Aug. 13 & Sep. 02 & Difference \\
\hline \multirow{4}{*}{ N1 } & The $1^{\text {st }}$ leaf from the top & $50.6 \pm 1.6^{\mathrm{b}}$ & $40.2 \pm 1.8^{\mathrm{b}}$ & $10.4 \pm 1.21^{\mathrm{a}}$ \\
\hline & The $2^{\text {nd }}$ leaf from the top & $52.7 \pm 1.2^{\mathrm{b}}$ & $43.8 \pm 1.4^{\mathrm{b}}$ & $8.9 \pm 0.83^{b}$ \\
\hline & The $3^{\text {rd }}$ leaf from the top & $54.8 \pm 1.5^{\mathrm{a}}$ & $47.5 \pm 2.5^{\mathrm{a}}$ & $7.3 \pm 0.68^{b}$ \\
\hline & The $4^{\text {th }}$ leaf from the top & $56.8 \pm 1.3^{\mathrm{a}}$ & $51.6 \pm 4.1^{\mathrm{a}}$ & $5.2 \pm 0.49^{c}$ \\
\hline \multirow{4}{*}{ N2 } & The $1^{\text {st }}$ leaf from the top & $52.5 \pm 1.8^{\mathrm{b}}$ & $43.2 \pm 1.9^{\mathrm{b}}$ & $9.3 \pm 0.91^{\mathrm{a}}$ \\
\hline & The $2^{\text {nd }}$ leaf from the top & $54.3 \pm 2.8^{\mathrm{b}}$ & $46.2 \pm 3.2^{b}$ & $8.1 \pm 0.79^{b}$ \\
\hline & The $3^{\text {rd }}$ leaf from the top & $54.6 \pm 3.5^{\mathrm{a}}$ & $49.6 \pm 3.2^{\mathrm{a}}$ & $5.0 \pm 0.48^{c}$ \\
\hline & The $4^{\text {th }}$ leaf from the top & $56.6 \pm 0.8^{\mathrm{a}}$ & $53.2 \pm 2.4^{\mathrm{a}}$ & $3.4 \pm 0.28^{c}$ \\
\hline \multirow{4}{*}{ K1 } & The $1^{\text {st }}$ leaf from the top & $50.5 \pm 2.2^{\mathrm{b}}$ & $40.4 \pm 2.0^{\mathrm{b}}$ & $10.1 \pm 1.12^{\mathrm{a}}$ \\
\hline & The $2^{\text {nd }}$ leaf from the top & $52.5 \pm 1.6^{\mathrm{b}}$ & $43.7 \pm 2.3^{b}$ & $8.8 \pm 0.84^{b}$ \\
\hline & The $3^{\text {rd }}$ leaf from the top & $54.8 \pm 4.0^{\mathrm{a}}$ & $47.6 \pm 3.1^{\mathrm{a}}$ & $7.2 \pm 0.68^{\mathrm{b}}$ \\
\hline & The $4^{\text {th }}$ leaf from the top & $56.7 \pm 1.5^{\mathrm{a}}$ & $51.0 \pm 3.2^{\mathrm{a}}$ & $5.7 \pm 0.55^{c}$ \\
\hline \multirow{4}{*}{ K2 } & The $1^{\text {st }}$ leaf from the top & $51.8 \pm 2.2^{\mathrm{b}}$ & $42.3 \pm 1.6^{\mathrm{b}}$ & $9.5 \pm 0.86^{\mathrm{a}}$ \\
\hline & The $2^{\text {nd }}$ leaf from the top & $53.9 \pm 2.4^{\mathrm{b}}$ & $45.8 \pm 1.8^{\mathrm{b}}$ & $8.1 \pm 0.91^{b}$ \\
\hline & The $3^{\text {rd }}$ leaf from the top & $56.5 \pm 3.6^{\mathrm{a}}$ & $49.6 \pm 3.7^{\mathrm{a}}$ & $6.9 \pm 0.72^{b}$ \\
\hline & The $4^{\text {th }}$ leaf from the top & $58.7 \pm 3.8^{\mathrm{a}}$ & $53.3 \pm 3.5^{\mathrm{a}}$ & $5.4 \pm 0.61^{\mathrm{c}}$ \\
\hline
\end{tabular}

Note: "Difference" means the SPAD values on Aug. 13 minus the SPAD values on Sep. 02. Values in the same column followed by different letters indicate significant differences (Duncan $\mathrm{P}<0.05$ ).

Table 4. Effect of $\mathrm{N}$ and $\mathrm{K}$ fertilizer application rate on SPAD values of upper leaves of cotton plant of SCRC 28.

\begin{tabular}{|c|c|c|c|c|}
\hline Treatments & Leaf site & Aug. 06 & Sep. 05 & Difference \\
\hline \multirow{5}{*}{ N1 } & The $1^{\text {st }}$ leaf from the top & $53.7 \pm 1.7^{\mathrm{a}}$ & $51.4 \pm 1.9^{\mathrm{a}}$ & $2.6 \pm 0.25^{\mathrm{c}}$ \\
\hline & The $2^{\text {nd }}$ leaf from the top & $55.6 \pm 0.9^{\mathrm{a}}$ & $52.2 \pm 2.0^{\mathrm{a}}$ & $3.4 \pm 0.33^{\mathrm{b}}$ \\
\hline & The $3^{\text {rd }}$ leaf from the top & $54.6 \pm 1.4^{\mathrm{a}}$ & $50.3 \pm 2.2^{\mathrm{a}}$ & $4.3 \pm 0.41^{\mathrm{a}}$ \\
\hline & The $4^{\text {th }}$ leaf from the top & $55.2 \pm 1.0^{\mathrm{a}}$ & $52.5 \pm 2.0^{\mathrm{a}}$ & $1.7 \pm 0.15^{\mathrm{c}}$ \\
\hline & The $1^{\text {st }}$ leaf from the top & $56.7 \pm 1.6^{\mathrm{a}}$ & $55.8 \pm 1.9^{\mathrm{a}}$ & $0.9 \pm 0.08^{\mathrm{b}}$ \\
\hline \multirow{3}{*}{ N2 } & The $2^{\text {nd }}$ leaf from the top & $56.8 \pm 3.0^{\mathrm{a}}$ & $56.1 \pm 3.1^{\mathrm{a}}$ & $0.7 \pm 0.06^{\mathrm{c}}$ \\
\hline & The $3^{\text {rd }}$ leaf from the top & $57.6 \pm 3.3^{\mathrm{a}}$ & $54.4 \pm 4.0^{\mathrm{a}}$ & $3.2 \pm 0.28^{\mathrm{a}}$ \\
\hline & The $4^{\text {th }}$ leaf from the top & $58.2 \pm 0.6^{\mathrm{a}}$ & $57.5 \pm 3.3^{\mathrm{a}}$ & $1.0 \pm 0.09^{\mathrm{b}}$ \\
\hline \multirow{4}{*}{ K1 } & The $1^{\text {st }}$ leaf from the top & $53.5 \pm 2.3^{\mathrm{a}}$ & $51.6 \pm 6.2^{\mathrm{a}}$ & $1.9 \pm 0.17^{\mathrm{c}}$ \\
\hline & The $2^{\text {nd }}$ leaf from the top & $55.7 \pm 1.4^{\mathrm{a}}$ & $52.7 \pm 5.5^{\mathrm{a}}$ & $3.0 \pm 0.28^{\mathrm{b}}$ \\
\hline & The $3^{\text {rd }}$ leaf from the top & $54.8 \pm 1.3^{\mathrm{a}}$ & $50.6 \pm 1.6^{\mathrm{a}}$ & $4.2 \pm 0.39^{\mathrm{a}}$ \\
\hline & The $4^{\text {th }}$ leaf from the top & $55.3 \pm 3.8^{\mathrm{a}}$ & $52.8 \pm 0.4^{\mathrm{a}}$ & $2.5 \pm 0.28^{\mathrm{b}}$ \\
\hline \multirow{4}{*}{ K2 } & The $1^{\text {st }}$ leaf from the top & $55.2 \pm 3.6^{\mathrm{a}}$ & $54.6 \pm 6.3^{\mathrm{a}}$ & $0.6 \pm 0.05^{c}$ \\
\hline & The $2^{\text {nd }}$ leaf from the top & $56.5 \pm 2.4^{\mathrm{a}}$ & $54.7 \pm 2.4^{\mathrm{a}}$ & $1.8 \pm 0.15^{\mathrm{b}}$ \\
\hline & The $3^{\text {rd }}$ leaf from the top & $57.6 \pm 2.1^{\mathrm{a}}$ & $54.8 \pm 1.3^{\mathrm{a}}$ & $2.8 \pm 0.26^{\mathrm{a}}$ \\
\hline & The $4^{\text {th }}$ leaf from the top & $57.8 \pm 4.3^{\mathrm{a}}$ & $56.7 \pm 3.1^{\mathrm{a}}$ & $1.1 \pm 0.10^{c}$ \\
\hline
\end{tabular}

Note: "Difference" means the SPAD values on Aug. 06 minus the SPAD values on Sep. 05. Values in different same column letters indicate the followed by significant differences (Duncan $\mathrm{P}<0.05$ ). 
rophyll b and the photosynthetic capacity of leaves [26]. Measuring chlorophyll content is a non-destructive way to obtain real time information on the chlorophyll and $\mathrm{N}$ content of crop plants. We sought to study the dynamic changes in chlorophyll and $\mathrm{N}$ of cotton plants, in order to diagnose the physiological and nutrient status of the plants [27]. This study showed that changes in SPAD values in the first leaf of two early-maturing cultivars and the third leaf of two early-maturing cultivars during late-stage growth could be used as a reference to diagnose senescence of a cotton plant.

\section{Conclusion}

In this study, we investigated the rule of SPAD values in cotton leaves of several cultivars during the whole growth period. We found that SPAD values in early-maturing and medium-maturing cultivars followed the rule: first leaves $<$ second leaves $<$ third leaves $<$ fourth leaves. The lowest SPAD values of the two early-maturing cultivars and two media-maturing cultivars occurred either before or after the flowering stage, suggesting important physiological transitions from vegetative to reproductive growth, when $\mathrm{N}$ in the leaf blades begins to transfer to the reproductive organs. After applying $\mathrm{N}$ fertilizers during the flowering period, the SPAD values began to rise and reached a peak during the boll period, declining again at the boll opening period. The difference of SPAD values of the 1st leaves from the top of main stem of cotton plants at $10 \mathrm{~d}$ before boll opening stage and $10 \mathrm{~d}$ after boll-opening stage could be a reference to diagnose senescence of early-maturing cotton plants. As to mid-maturing cultivar, the difference of SPAD values of the 3rd leaves from the top of main stem of cotton plants at about $15 \mathrm{~d}$ before boll opening stage and $15 \mathrm{~d}$ after boll opening stage could be a reference to diagnose senescence of mid-maturing cotton plants.

\section{Acknowledgements}

This study was sponsored by State Key Laboratory of Cotton Biology Open Fund (CB2014A18) and a grant from The Modern Agro-Industry Technology Research System (Cotton 2011-2015).

\section{References}

[1] Bob Wiedenfeld, B., Webb Wallace and Frank Hons (2009) Indicators of Cotton N Status. Journal of Plant Nutrition, 32, 1353-1370. http://dx.doi.org/10.1080/01904160903006044

[2] Judith G C, Kenji O. (1990) Chlorophyll a Fluorescence and Carbon Assimilation in Developing Leaves of Light-Grown Cucumber. Plant Physiol, 93, 1078-1082. http://dx.doi.org/10.1104/pp.93.3.1078

[3] Wang S H, Cao W X, Wang Q S, Ding Y F, Huang P S, Ling Q H. (2002) Positional Distribution of Leaf Color and Diagnosis of N Nutrition in Rice Plant. Scientia Agricultura Sinica, 35, 1461-1466 (in Chinese with English Abstract).

[4] Li Z H, Liu H B, Zhang Y G. (2006) A Review on Chlorophyll Meter Application on N Fertilizer Recommendation. Acta Metallurgica Sinica, 12, 125-132 (in Chinese with English Abstract).

[5] Hu H, Bai Y L, Yang L P, Lu Y L, Wang L, Wang H, Wang Z Y. (2010) Diagnosis of N Nutrition in Winter Wheat (Triticum aestivum) via SPAD-502 and Green Seeker. Chinese Journal of Eco-Agriculture, 18, 748-752 (in Chinese with English Abstract). http://dx.doi.org/10.3724/SP.J.1011.2010.00748

[6] Jiang B W, Dai J J, Wang C H, Wang L J, Jia W K, Chi F Q. (2010) Effect of N Management on the Relationship of Leaf SPAD with N Absorption of Corn in Cold Area. Soil and Fertilizer Sciences in China, 3, 41-44 (in Chinese with English Abstract).

[7] Qiu Z J, Song H Y, He Y, Fang H. (2010) Variation Rules of the N Content of the Oilseed Rape at Growth Stage Using SPAD and Visible-NIR. Transactions of the Chinese Society of Agricultural Engineering, 3, 41-44 (in Chinese with English Abstract).

[8] Nie X R, Fan M S. (2010) Diagnosis of Potato N Nutrition Status by Use of Chlorophyll Meter SPAD-502. Chinese Potato Journal, 3, 41-44 (in Chinese with English Abstract).

[9] Hong J, Chen G, Zhang L H, Huang X, Ge M H, Wang H T, Yang H Q, Bi Q R. (2010) Study on N Nutrition Status of Citrullus Lanatus by Chlorophyll Meter. Journal of Changjiang Vegetables, 8, 82-85 (in Chinese with English Abstract).

[10] Wu F B, Xu F H, Jin Z Q. (1999) A Preliminary Study on N Nutrition Diagnosis for Short-Season Cotton with a Chlorophyll Meter. Acta Agronomica Sinica, 25, 483-488 (in Chinese with English Abstract).

[11] El-Shikha, D.M., Barnes, E.M., Clarke, T.R., Hunsaker, D.J., Haberland, J.A., Pinter Jr., P.J., Waller, P.M. and Thompson, T.L. (2008) Remote Sensing of Cotton N Status Using the Canopy Chlorophyll Content Idex (CCCI). 
American Society of Agricultural and Biological Engineers, 51, 73-82.

[12] Zhu, X.K., Sheng, H.J., Gu, J., Zhang, R. and Li, C.Y. (2005) Primary Study on Application of SPAD Value to Estimate Chlorophyll and N Content in Wheat Leaves. Journal of Triticeae Crops, 25, 46-50 (in Chinese with English Abstract).

[13] Wu, X.Y., Guo, J.H., Fang, Z. and Zhang, Y.G. (2010) The Application of SPAD on N Diagnosis of Cucumber. Northern Horticulture, 11, 13-16 (in Chinese with English Abstract).

[14] Li, L.L., Fang, W.P., Xie, D.Y., Ma, Z.B., Du, Y.F. and Zhang, D.L. (2010) Effects of N Application Rates on Photosynthetic and Physiological Characteristics and Yield and Quality of Hybrid Cotton. Plant Nutrition and Fertilizer Science, 16, 1183-1189 (in Chinese with English Abstract).

[15] Wang, F.Y., Wang, K.R., Li, S.K., Chen, B. and Chen, J. (2010) Estimation of Chlorophyll and N Contents in Cotton Leaves Using Digital Camera and Imaging Spectrometer. Acta Agronomica Sinica, 36, 1981-1989.

[16] Zhi, J.H., Wu, W.M., Wei, C.Z., Dong, H.L., Chen, K.W. and Yang, R.B. (2007) Chlorophyll Space-Time Distributing of Cotton Leaves by Water and N in Filmed Field by Drip Irrigation. Acta Agriculturae Boreali-Occidentalis Sinica, 16, 7-12 (in Chinese with English Abstract).

[17] Luo, X.N., Chen, B., Zhang, J.S., Jiang, P.A., Lou, S.W., Peng, X.F. and He, J.L. (2009) Study on the Spatial Distribution of Leaf SPAD Value in Cotton. Cotton Science, 21, 427-430 (in Chinese with English Abstract).

[18] Qu, W.Q., Wang, S.H., Chen, B.L., Wang, Y.H. and Zhou, Z.G. (2007) SPAD Value of Cotton Leaves on Main Stem and N Diagnosis for Cotton Growth. Acta Agronomica Sinica, 33, 1010-1017 (in Chinese with English Abstract).

[19] Hao, J.J., Liu, H.M., Ma, Q.X., Cui, X.W., Yu, J.W., Jia, X.H. and Gao, J.S. (2011) Genetic Effects and Diagnosis of Premature Senescence of Leaf in Upland Cotton. Acta Agronomica Sinica, 37, 389-396 (in Chinese with English Abstract). http://dx.doi.org/10.3724/SP.J.1006.2011.00389

[20] Wu, F.B., Xu, F.H. and Jin, Z.Q. (1999) A Preliminary Study on N Nutrition Diagnosis for Short-Season Cotton with a Chlorophyll Meter. Acta Agronomica Sinica, 25, 483-488 (in Chinese with English Abstract).

[21] Wood, C.W., Tracy, P.W., Reeves, D.W. and Edmisten, K.L. (1992) Determination of Cotton N Status with a Hand-Held Chlorophyll Meter. Journal of Plant Nutrition, 15, 1435-1448. http://dx.doi.org/10.1080/01904169209364409

[22] Johnson, J.R. and Saunders, J.R. (2003) Evaluation of Chlorophyll Meter for N Management in Cotton. Annual Report 2002 of the North Mississippi Research and Extension Center. Mississippi Agriculture and Forestry Experiment Station Bulletin, 398, 162-163.

[23] Cetin, K., Emine, K., Remzi, E. and Oktay, G. (2009) Correlations and Path Coefficient Analysis between Leaf Chlorophyll Content, Yield and Yield Components in Cotton (Gossypium hirsutum L.) under Drought Stress Conditions. Notulae Botanicae Horti Agrobotanici Cluj-Napoca, 37, 241-244.

[24] Rosolem, C.A. and Van Mellis, V. (2010) Monitor N Nutrition in Cotton. Revista Brasileira de Ciência do Solo, 34, 1601-1607. http://dx.doi.org/10.1590/S0100-06832010000500013

[25] Raper, T.B., Oosterhuis, D.M., Siddons, U., Purcell, L.C. and Mozaffari, M. (2012) Utilization of the Dark Green Color Index to Determine Cotton N Status. Research Series-Arkansas Agricultural Experiment Station, 599, 34-36.

[26] Blackburn, G.A. (2002) Remote Sensing of Forest Pigments Using Air-Borne Imaging Spectrometer and LIDAR Imagery. Remote Sensing of Environment, 82, 311-321. http://dx.doi.org/10.1016/S0034-4257(02)00049-4

[27] Wang, L., Zhu, J.R., Yang, T., Wang, B., Yang, J.Y., Chen, B.Y., Liu, H., Xu, Y.M., Ma, X.W. and Zhao, D.C. (2010) Effects of N Fertilize Strategies on Chlorophyll Content in Leaf of Cotton under Mulch-Film Drip Irrigation. Cotton Science, 22, 454-459 (in Chinese with English Abstract). 
Scientific Research Publishing (SCIRP) is one of the largest Open Access journal publishers. It is currently publishing more than 200 open access, online, peer-reviewed journals covering a wide range of academic disciplines. SCIRP serves the worldwide academic communities and contributes to the progress and application of science with its publication.

Other selected journals from SCIRP are listed as below. Submit your manuscript to us via either submit@scirp.org or Online Submission Portal.
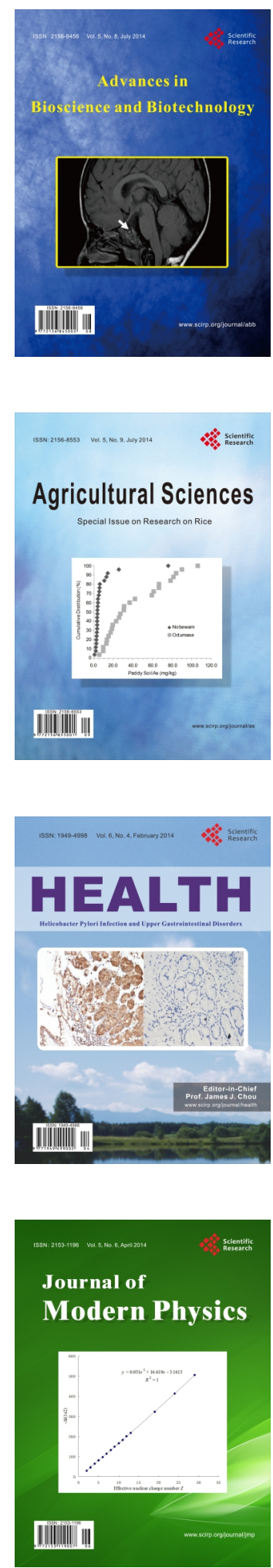
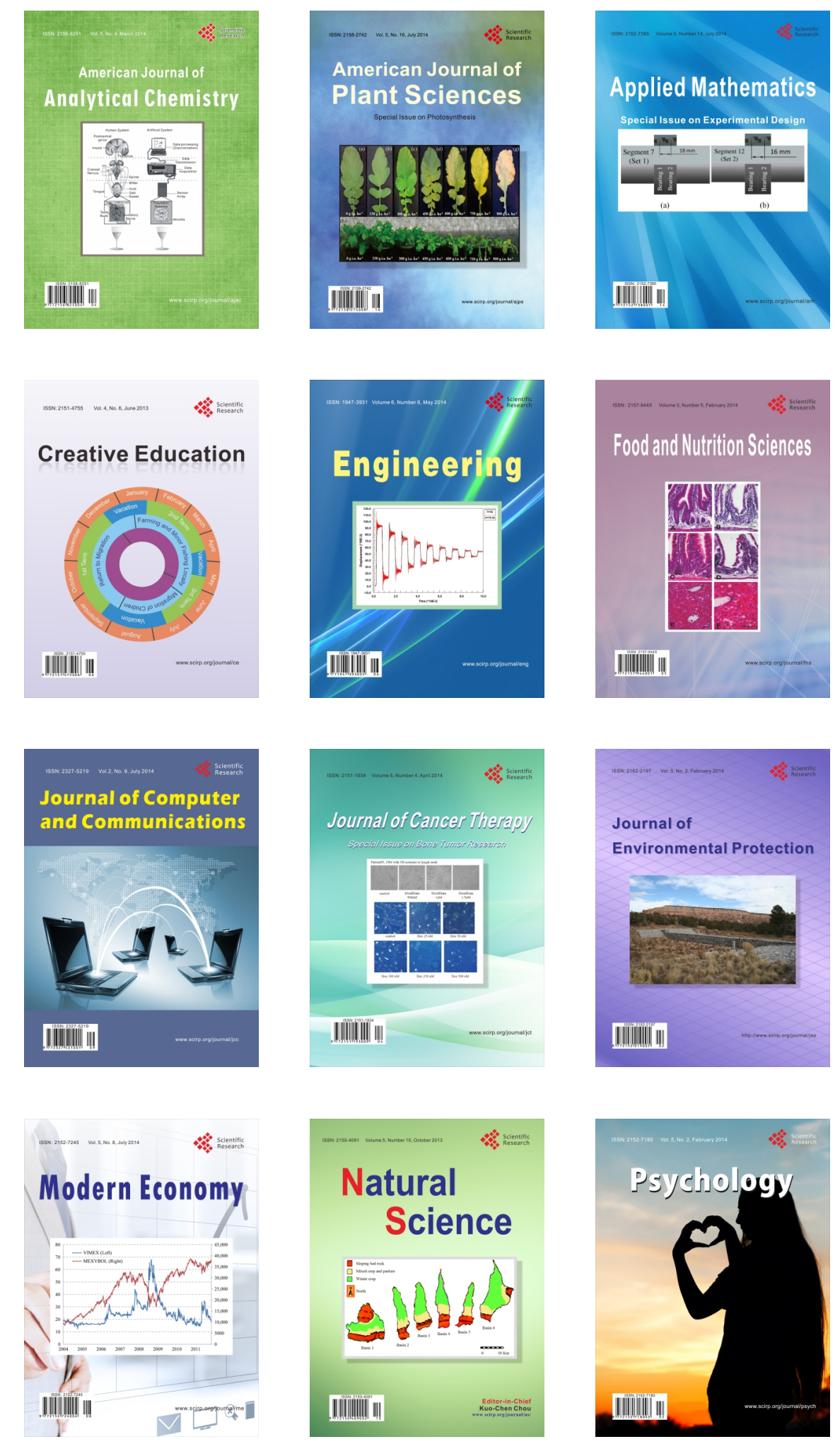